\title{
Up-regulation of Stearoyl-CoA Desaturase 1 Increases Liver MUFA Content in Obese Zucker but not Goto-Kakizaki Rats
}

Minako Karahashi $^{\mathrm{a}} \cdot$ Fumiko Ishii $^{\mathrm{aq}} \cdot$ Tohru Yamazaki $^{\mathrm{a}} \cdot$ Koichi Imai $^{\mathrm{b}} \cdot$ Atsushi Mitsumoto $^{\mathrm{c}}$. Yoichi Kawashima ${ }^{\mathrm{a}} \cdot$ Naomi Kudo ${ }^{*, \text { a }}$

${ }^{a}$ Faculty of Pharmaceutical Sciences, Josai University, 1-1 Keyakidai, Sakado, Saitama 350-0295, Japan

${ }^{b}$ Saitama Prefectural Institute of Public Health, 639-1 Kamiokubo, Sakura-ku, Saitama 338-0824, Japan

${ }^{c}$ Faculty of Pharmaceutical Sciences, Josai International University, 1 Gumyo, Togane, Chiba 283-8555, Japan

*To whom correspondence should be addressed: Faculty of Pharmaceutical Sciences, Josai University, 1-1 Keyakidai, Saitama 350-0295, Japan

E-mail: naokudo@josai.ac.jp

Tel. : +81-49-271-7031

Fax: +81-49-271-7984

"Present address: Fumiko Ishii

CREATE SDS, 2-3-2 Edanishi, Aoba-ku, Aokohama, Kanagawa 225-0014, Japan

Abstract Goto-Kakizaki (GK) rat is an animal model for spontaneous-onset, non-obese 
type 2 diabetes. Despite abundant evidence about disorder in metabolism, little information is available about fatty acid metabolism in the liver of GK rats. This study aimed to investigate the characteristics of the fatty acid profile, particularly MUFA, and the mechanism underlying the alterations in fatty acid profile in the liver of GK rats. The activities of enzymes that participate in the biosynthesis of MUFA, expressions of genes encoding these enzymes, and fatty acid profile in the liver were compared with those of obese Zucker ( $f a / f a)(Z F)$ rats, which are obese and non-diabetic. Stearoyl-CoA desaturase (SCD) activity and SCD1 gene expression were considerably up-regulated in GK rats, and these levels were largely comparable to those in ZF rats. However, the proportions and contents of oleic acid and palmitoleic acid were very low considering the highly elevated activity of SCD in the liver of GK rats, when compared with ZF rats. Palmitoyl-CoA chain elongation (PCE) activity and fatty acid elongase (Elovl)6 gene expression were markedly up-regulated in ZF rats, whereas PCE activity was up-regulated much less and Elovl6 gene expression was unchanged in GK rats. These results suggest the possibility that up-regulation of gene expression of Elovl6 along with SCD1 is indispensable to elevate the proportions and contents of oleic acid in the liver.

Keywords Desaturase $\cdot$ Elongase Oleic acid · Palmitoleic acid · Goto-Kakizaki rat · Obese Zucker (fa/fa) rat

\section{Abbreviations}




\begin{tabular}{|c|c|}
\hline Elovl & Fatty acid elongase \\
\hline ER & Endoplasmic reticulum \\
\hline Fads & Fatty acid desaturase \\
\hline GK & Goto-Kakizaki \\
\hline NADH & Nicotinamide adenine dinucleotide reduced \\
\hline NADPH & Nicotinamide adenine dinucleotide phosphate reduced \\
\hline PCE & Palmitoyl-CoA chain elongation \\
\hline POCE & Palmitoleoyl-CoA chain elongation \\
\hline SCD & Stearoyl-CoA desaturase \\
\hline SHR & Spontaneously hypertensive \\
\hline SHR/NDcp & SHR/NDmcr-cp (cp/cp) \\
\hline SREBP-1C & Sterol regulatory element binding protein-1c \\
\hline STZ & Streptozotocin-induced diabetic \\
\hline VLDL & Very low-density lipoprotein \\
\hline WI & Wistar rats, a control corresponding to GK rats \\
\hline $\mathrm{ZF}$ & Obese Zucker (fa/fa) \\
\hline ZL & Lean Zucker (?/+) \\
\hline
\end{tabular}

\section{Introduction}


Biosynthesis of oleic acid (18:1n-9) from palmitic acid (16:0) in the liver is sequentially catalyzed by fatty acid elongase (Elovl) 6 and stearoyl-CoA desaturase (SCD)1, and palmitoleic acid (16:1n-7) is synthesized by SCD1 from 16:0 [1]. In general, SCD1 and Elovl6 are coordinately controlled [2-6]. There is increasing evidence that SCD and its products, 18:1n-9 and/or 16:1n-7, in the liver are of crucial importance for many physiological processes such as triacylglycerol (TAG) synthesis [1,7], endoplasmic reticulum (ER) stress [8-10], secretion of very low-density lipoprotein (VLDL) [11,12] and insulin sensitivity $[13,14]$. Metabolic diseases, dietary states and hormonal states are known to affect the proportions of monounsaturated fatty acids (MUFA) in hepatic lipids through changes in SCD activity [1]. Among the metabolic diseases, diabetes and obesity are of particular interest. It is well established that SCD activity is extremely low in the liver of streptozotocin-induced type 1 diabetic rats [6,15]. In contrast, SCD activities in the liver of $d b / d b$ mice, obese Zucker (fa/fa) (ZF) rats and spontaneously hypertensive (SHR)/NDmcr-cp (cp/cp) (SHR/NDcp) rats have been demonstrated to be markedly higher than those of their respective controls [16-18]. Moreover, the proportions of 18:1n-9 and 16:1n-7 in hepatic lipids of these animals are considerably higher than those of the respective control animals [17-19]. $d b / d b$ mice have a point mutation of the leptin receptor gene, and develop obesity, insulin resistance, hyperglycemia, hyperinsulinemia and hyperlipidemia associated with type 2 diabetes [20]. ZF rats have a mutated leptin receptor and, as a consequence, are hyperphagic, obese, hyperlipidemic and insulin-resistant, but do not develop diabetes [21]. SHR/NDcp rats carry a nonsense mutation of the leptin receptor gene; the rats spontaneously display typical symptoms of metabolic syndrome such as visceral obesity, hypertension, hyperlipidemia, hyperglycemia and hyperinsulinemia, and exhibit type 2 diabetes [22].

Goto-Kakizaki (GK) rats have been established from normal Wistar rats by selective breeding of animals with signs of impaired glucose tolerance [23]. GK rat is an animal model 
of spontaneous-onset, non-obese type 2 diabetes, featuring postprandial hyperglycemia, impaired glucose tolerance, impaired insulin secretion, progressive reduction of $\beta$-cell mass and the development of long-term diabetic complications [24,25]. The most important characteristic of GK rats with regard to lipid metabolism is that this rat has no mutation in the leptin receptor gene and is non-obese. GK rats thus offer a convenient model for the study of type 2 diabetes, without the confounding effects of obesity. It is necessary to determine the characteristics of fatty acid metabolism in the liver to establish GK rats as a useful model for research on non-obese type 2 diabetes, because hepatic fatty acid composition is considered to be a determinant of insulin sensitivity that acts independently of cellular energy balance and stress [26]. To date, however, abnormality of fatty acid metabolism and fatty acid profile in GK rats is poorly characterized, and the underlying molecular mechanism is essentially unexplored.

In this context, the present study aimed (i) to uncover the fatty acid profile of lipids and (ii) to reveal the roles of fatty acid desaturases and elongases in the regulation of the proportion of fatty acids, in particular MUFA, in the liver of GK rats, in comparison with those in ZF rats, which is one of the representative models of obesity without diabetes. In the present study, we demonstrated (i) that SCD activity is considerably enhanced in the liver of GK rats despite the rats not being obese, (ii) that the SCD activity is high considering the very low proportions and contents of MUFA in the liver of GK rats and (iii) that the gene expression of Elovl6 and the activity of palmitoyl-CoA chain elongation (PCE) in the liver of GK rats are markedly lower than those of ZF rats. The present study showed for the first time that up-regulation of the expression of the Elovl6 gene along with SCD1 is indispensable to increase the proportion and content of 18:1n-9 in the liver by utilizing rats with a spontaneously altered metabolic state.

\section{Materials and Methods}


Materials

$\left[2-{ }^{14} \mathrm{C}\right]$ Malonyl-CoA (55 Ci/mol) was purchased from Moravek Biochemicals (Brea, CA). Palmitoleoyl-CoA, palmitoyl-CoA, stearoyl-CoA, malonyl-CoA, streptozotocin and bovine serum albumin were purchased from Sigma-Aldrich Japan (Tokyo, Japan). Nonadecanoic acid was obtained from Nu-Chek-Prep Inc. (Elysian, MN). Nicotinamide adenine dinucleotide reduced (NADH) and nicotinamide adenine dinucleotide phosphate reduced (NADPH) were obtained from Oriental Yeast Co. (Tokyo, Japan). All other chemicals used were of analytical grade.

Animals

All animal procedures were approved by the Josai University’s Institutional Animal Care Committee in accordance with the Guidelines for Proper Conduct of Animal Experiments (Science Council of Japan). Five-week-old male lean Zucker (?/+) (ZL) and ZF rats were obtained from Charles River Japan (Tokyo, Japan). Animals were fed on a standard diet (CE-2, Clea Japan Inc.) (Tokyo, Japan) ad libitum and allowed free access to water. After acclimatization for at least 1 week, rats were used as follows. GK, WI, ZF and ZL rats were fed on the standard diet for 4 weeks and were then killed at the age of 10 weeks. WI rats aged 5 weeks were made diabetic by an intravenous injection of streptozotocin at a dose of 50-60 $\mathrm{mg} / \mathrm{kg}$ of body weight, as described previously $[6,15]$. The streptozotocin-induced diabetic (STZ) rats were fed on the standard diet, and were killed at the age of 10 weeks. Only those animals that showed blood glucose levels of more than $500 \mathrm{mg} / 100 \mathrm{~mL}$ were used. Animals were anesthetized with diethyl ether, and blood was withdrawn from the inferior vena cava. The liver was rapidly removed, washed with saline and weighed. For determination of mRNA, 
one part of the liver was frozen in liquid nitrogen and then stored at $-80^{\circ} \mathrm{C}$. The other part of the liver was perfused with ice-cold saline, and was used for preparation of microsomes.

Preparation of Microsomes

Livers were homogenized with 4 volumes of 0.25 M sucrose/1 mM EDTA/10 mM Tris-HCl (pH 7.4) in a Potter glass-Teflon homogenizer. The homogenates were centrifuged at 18,000 x g for $20 \mathrm{~min}$, and the supernatant was centrifuged under the same conditions. The resulting supernatant was centrifuged at 105,000 $\mathrm{x}$ g for $60 \mathrm{~min}$. The obtained pellet was then resuspended in 0.25 M sucrose/0.1 mM EDTA/10 mM Tris-HCl (pH 7.4) and recentrifuged under the same conditions. The resulting pellet was resuspended in a small volume of $0.25 \mathrm{M}$ sucrose/0.1 mM EDTA/10 mM Tris- $\mathrm{HCl}(\mathrm{pH} 7.4)$ and used as the microsome fraction. All operations were carried out at $0-4^{\circ} \mathrm{C}$. Protein concentrations were determined by the method of Lowry et al. [27] using bovine serum albumin as a standard.

Analysis of Fatty Acids

After the addition of a known amount of nonadecanoic acid as an internal standard, total lipid was extracted from the liver by the method of Bligh and Dyer [28]. Fatty acid methyl esters of hepatic lipids were prepared as described previously [17], and the acyl composition of these lipids was determined by gas-liquid chromatography (Shimadzu GC-2014; Kyoto, Japan), equipped with a flame-ionization detector, using a fused-silica capillary column (SLB-IL100, $30 \mathrm{~m}$ x $0.32 \mathrm{~mm}$ internal diameter, film thickness $0.26 \mu \mathrm{m}$, Sigma-Aldrich), as described previously [29].

Enzyme Assays 
The activities of SCD in microsomes were determined spectrophotometrically as described previously $[6,15,17]$ and the activity is presented as the rate constant $\left(k^{+}\right)$for stearoyl-CoA stimulated re-oxidation of NADH-reduced cytochrome $b_{5}$. PCE and palmitoleoyl-CoA chain elongation (POCE) in microsomes were assayed as the activities of conversion of palmitoyl-CoA to $\left[{ }^{14} \mathrm{C}\right]$ stearic acid $(18: 0)$ and that of palmitoleoyl-CoA to $\left[{ }^{14} \mathrm{C}\right]$ cis-vaccenic acid (18:1n-7), respectively, by estimating the incorporation of the C2 unit from $\left[2-{ }^{14} \mathrm{C}\right]$ malonyl-CoA, essentially according to a method reported previously [30]. In brief, the assay mixture contained $15 \mathrm{nmol}$ palmitoyl-CoA or palmitoleoyl-CoA, $100 \mathrm{nmol}$ [2- ${ }^{14}$ C]malonyl-CoA (20 nCi), $1 \mu$ mol NADPH, $1 \mu$ mol NADH, $0.5 \mu \mathrm{mol} \mathrm{KCN,} \mathrm{200-250} \mu \mathrm{g}$ of microsomal protein and $100 \mathrm{mM}$ Tris- $\mathrm{HCl}(\mathrm{pH} 7.4)$ in a total volume of $0.5 \mathrm{~mL}$. The incubation was performed at $37^{\circ} \mathrm{C}$ for 4 min under nitrogen.

RNA Isolation and Analysis of Gene Expression

Total RNA was isolated from liver tissues using QIAzol reagent and RNeasy kit (QIAGEN, Hilden, Germany). cDNA was synthesized from 500 ng of total RNA with avian myeloblastosis virus reverse transcriptase (Takara, Shiga, Japan). Polymerase chain reaction (PCR) amplification was carried out using SYBR Premix EX Tag (2x) (Perfect Real Time) (Takara). The amplification and detection were performed with Applied Biosystems 7500 real time PCR system (Life Technologies Corp., Carlsbad, CA). The thermal cycling program was as follows: $10 \mathrm{~s}$ denaturation step at $95^{\circ} \mathrm{C}$, followed by 50 cycles of $5 \mathrm{~s}$ denaturation at $95^{\circ} \mathrm{C}$ and $34 \mathrm{~s}$ annealing at $60^{\circ} \mathrm{C}$. Melting curve analysis was performed to confirm the real-time PCR products. Changes in gene expression were calculated by using the comparative threshold cycle $(\mathrm{Ct})$ method. Ct values were first normalized by subtracting the Ct value obtained from $\beta$-actin (control). The sequences of primers used in this study are listed in Table 
Statistical Analysis

Homogeneity of variance was established using one-way analysis of variance. When a difference was significant $(p<0.05)$, Scheffé's multiple range test was used as a post hoc test. The statistical significance between two groups was analyzed by Student's $t$-test after $F$-test. The results were considered as statistically significant with a value of $p<0.05$.

\section{Results}

SCD Activities in STZ, GK and ZF Rats

SCD activities in hepatic microsomes of STZ, GK, ZF and their respective control rats were estimated (Fig. 1). SCD activity in STZ rats was $21 \%$ of that in WI rats, although the difference was not statistically significant. In contrast, SCD activities in GK and ZF rats were higher (363 and 670\%, respectively) than those in their respective controls, WI and ZL rats. No significant difference was observed in the activity between WI and ZL. It is noteworthy that the activity of SCD in GK rats corresponded to $61 \%$ of that in ZF rats.

Profile of MUFA in GK and ZF Rats

To understand the characteristics of MUFA synthesis in the liver of GK rats, the fatty acid composition of hepatic lipids was analyzed. Table 2 shows the fatty acid profile (mole \%) of hepatic lipids of GK rats in comparison with that of ZF rats. There were no significant differences in fatty acid profile in hepatic lipids between WI and ZL rats, except for 
8,11,14-eicosatrienoic acid (20:3n-6). The proportion of 18:1n-7 in the liver of GK rats was higher (132\%) than those of WI rats, whereas no significant change was observed in the proportion of 18:1n-9 between GK and WI rats. The proportion of 16:1n-7 in hepatic lipid of GK rats was higher (166\%) than that of WI rats, the difference being not statistically significant. In the liver of ZF rats, the proportions of 18:1n-9, 16:1n-7 and 18:1n-7 were higher (294, 469 and 151\%, respectively) than those of ZL rats. Fig. 2 shows the differences in content ( $\mu$ mole/g liver) of a particular fatty acid between two groups of rats. The differences in mass of 18:1n-9 between ZF and ZL rats and between GK and WI rats were 30.82 and $1.69 \mu \mathrm{mol} / \mathrm{g}$ liver, respectively. Those of 16:1n-7 between ZF and ZL rats and between GK and WI rats were 10.91 and $1.03 \mu \mathrm{mol} / \mathrm{g}$ liver, respectively. Those of 18:1n-7 between ZF and ZL rats and between GK and WI rats were 5.30 and $1.31 \mu \mathrm{mol} / \mathrm{g}$ liver, respectively. Thus, among the MUFA, the extents of the increases in the proportions and contents of 18:1n-9 and 16:1n-7 in GK rats were markedly lower than those in ZF rats. On the other hand, no considerable difference was observed in the proportion of 18:1n-7 between GK and ZF rats.

Desaturases and Elongases Involved in Biosynthesis of MUFA

The microsomal activities of PCE and POCE in the liver were determined (Fig. 3). The activity of PCE in GK rats was higher (136\%) than that in WI rats. On the other hand, PCE activity in ZF rats was higher (250\%) than that of ZL rats (Fig. 3A). The activity of PCE in GK rats was $63 \%$ of that in ZF rats. No considerable difference was observed in PCE activity between WI and ZL rats. No notable difference was observed in POCE activity among GK, ZF and WI rats (Fig. 3B).

The levels of mRNA encoding key enzymes that control MUFA composition of hepatic lipids in the liver of GK rats were estimated in comparison with those of ZF rats (Fig. 4). With 
regard to the expression of genes encoding SCD, the levels of SCD1 mRNA in GK and ZF rats were higher (192 and 889\%, respectively) than those of their respective controls. The level of SCD1 mRNA in ZF rats was higher (169\%) than that in GK rats. There was no difference in the expression of SCD2 gene among the four groups of rats. As for Elovls, the level of Elovl6 mRNA in ZF rats was higher (2930\%) than that of ZL rats. The level of Elovl6 mRNA in GK rats was $5.6 \%$ of that in ZF rats. There was no significant difference in the level of Elovl6 mRNA between WI and GK rats. The level of Elovl5 mRNA in GK rats was higher (158\%) than that in WI rats. The level of Elovl5 mRNA in ZF rats was $49 \%$ of that in GK rats, and no significant difference was observed in the level of Elovl5 mRNA between ZL and ZF rats.

Profile of Polyunsaturated Fatty Acid (PUFA) in GK and ZF Rats

There was a marked difference in the composition of PUFA in the liver between ZF and ZL rats (Table 2). Proportions of arachidonic acid (20:4n-6) and linoleic acid (18:2n-6) in ZF rats were 40 and 61\%, respectively, of those in ZL rats, but hepatic content of 18:2n-6 in the liver of ZF rats was almost the same as that of ZL rats (23.1 vs. $25.0 \mu$ mole/g liver). The proportion of 20:3n-6 in ZF rats was higher (179\%) than that in ZL rats. On the other hand, no significant difference was found in the proportions of 20:4n-6 and 20:3n-6 between GK and WI rats, whereas the proportion of $18: 2 n-6$ in GK rats was $80 \%$ of that in WI rats. As shown in Fig. 4, the mRNA level of fatty acid desaturase (Fads)1 in GK rats was higher (184\%) than that in WI rats. The level of Fads1 mRNA in ZF rats was 31\% of that in ZL rats and was $18 \%$ of that in GK rats. There was no significant difference in gene expression of Fads2 among WI, GK and ZL rats. The mRNA level of Fads2 in ZF rats was 79\% of that in ZL rats and was 54\% of that in GK rats. 


\section{Discussion}

SCD has received considerable attention for its regulation by hormones and nutrients and its capacity to generate MUFA. In terms of hormones, insulin strongly regulates SCD in the liver, so that this activity is suppressed in animal models of type 1 diabetes such as STZ rats $[6,15]$. In contrast, the activity is reported to be profoundly augmented in the liver of obese animals that carry mutated leptin receptor gene such as ZF rats [17,31]. In accordance with these previous findings, our current study confirmed that SCD activity in the liver of STZ rats showed an obvious tendency to be lower and that the activity in the liver of ZF rats is strikingly high. Interestingly, the present study provided evidence that the activity of SCD in the liver of GK rats is at an intermediate level in ZF and control rats and is much higher than that in STZ rats. The activity in GK rats (estimated as rate constant $k^{+}=3.2$ ) corresponded to $61 \%$ of that in ZF rats $\left(k^{+}=5.2\right)$ and is comparable to the SCD activity in SHR/NDcp rats $\left(k^{+}\right.$ = 3.8). SHR/NDcp rats display markedly enhanced activity of SCD and abnormally high proportions of 18:1n-9 and 16:1n-7 in their liver [18]. To the best of our knowledge, this is the first evidence showing that the SCD activity in the liver of diabetic and non-obese animals is augmented up to a level comparable to that of obese rats. These results prompted us to anticipate elevated proportions of MUFA in the liver of GK rats. The analyses of fatty acid composition revealed, however, that a notable increase did not occur in the proportions and contents of MUFA in hepatic lipids of GK rats, whereas striking elevations of the proportions and contents of MUFA, in particular 18:1n-9 and 16:1n-7, were confirmed in hepatic lipids of ZF rats. These results strongly indicate that the proportions and contents of 18:1n-9 and 16:1n-7 are very low considering the high activity of SCD in the liver of GK rats.

Fatty acids are synthesized de novo from acetyl-CoA, and the liver modifies fatty acid structure through a metabolic pathway that includes fatty acid desaturation and chain elongation. Such modifications occur to fatty acids generated de novo as well as fatty acids 
derived from the diet. In contrast to SCD, elongases have only recently been recognized as important contributors to the regulation of hepatic lipid composition [5]. To elucidate the mechanism underlying the fatty acid profile in the liver of GK rats, we estimated the activities of PCE and POCE in hepatic microsomes of GK rats and compared the results with those from ZF rats. The activity of PCE in GK rats was slightly higher than that in control rats. On the other hand, PCE activity in ZF rats was much higher (250\%) than that in corresponding control rats. The case of POCE was entirely different from that of PCE. Roughly, there was no marked difference in POCE activity among GK, ZF, and their corresponding control rats.

To gain insights into the molecular basis of regulation of SCD, PCE and POCE, the expressions of genes encoding SCD and fatty acid elongases were estimated. For SCD, two genes encoding the enzyme have been reported in the liver of rats [32]. Of these subtypes, SCD1 is expressed at a high level in the liver of animals with altered pathophysiological states, such as ZF and SHR/NDcp rats $[1,14,17,18]$. The present study demonstrated that the gene expression of SCD1 in GK rats was approximately 2 times higher than that in control rats. In accordance with previous studies [17], the expression of SCD1 gene in ZF rats was profoundly higher than that in ZL rats. Consequently, the level of SCD1 mRNA in the liver of ZF rats was higher (889\%) than that of ZL rats, and was higher (169\%) than that of GK rats. On the other hand, there was no significant difference in the expression of the gene encoding SCD2 among GK, ZF and their respective control rats. As for Elovls, Elovl6 expression was strikingly high in the liver of only ZF rats, whereas the level of Elovl6 expression in GK rats was only $5.6 \%$ of that in ZF rats. On the other hand, the expression of Elovl5 in GK rats was slightly, but significantly, higher than that in control rats and was about 2 times higher than that in ZF rats. The translated product of Elovl6 is considered to have a substrate preference for $16: 0$ [5,33]. Elovl5 product preferentially converts $16: 1 n-7$ to $18: 1 n-7$, whereas $16: 0$ is a poor substrate for this protein $[5,33]$. On the basis of these findings, in a previous study on SHR/NDcp rats, we developed the hypothesis that PCE is largely composed of Elovl6 product 
and that POCE consists of two elongases with a relatively large proportion of Elovl5 product and a relatively small proportion of Elovl6 product [18]. This hypothesis may enable us to explain the difference in the proportions of MUFA between GK and ZF rats (Fig. 5). Namely, in the liver of ZF rats, the activities of SCD and PCE were markedly high, primarily due to the enhanced gene expressions of both SCD1 and Elovl6, but the activity of POCE was not altered, owing to unchanged expression of the Elovl5 gene, so that the proportions and contents of $18: 1 n-9$ and 16:1n-7 were strikingly elevated, but that of $18: 1 n-7$ was increased to a lesser extent. On the other hand, in the liver of GK rats, the activity of SCD was up-regulated, due to substantial increase in SCD1 expression. As for fatty acid elongase in GK rats, however, the activity of PCE was slightly enhanced, with no statistically significant difference in Elovl6 expression between GK and control rats; conversely, despite the expression of Elovl5 in GK rats being considerably higher than that in control rats, the activity of POCE in GK rats was slightly, but not significantly, higher than that in control rats, so that the proportions of MUFA were little changed. These results would indicate that transcription levels may not be directly related to enzyme activities. It still remains to be resolved why the proportion and content of 16:1n-7 were very low considering the high activity of SCD in the liver of GK rats. It is worth noting, however, that contents of 16:0, which is a substrate for the synthesis of $16: 1 \mathrm{n}-7$ or $18: 1 \mathrm{n}-9$ via stearic acid (18:0), in the liver of GK and ZF rats were 23.87 and $58.46 \mu$ mole/g liver, respectively, and the difference in mass of 16:0 between ZF and ZL rats and between GK and WI rats were 28.83 and 1.53 $\mu$ mole/g liver, respectively. One may suspect, therefore, the possibility that SCD in the liver of ZF rats is able to utilize large amounts of 16:0 as substrate; on the other hand, 16:0 is less available for SCD in the liver of GK rats, despite the fact that the SCD activities in GK and ZF rats are roughly similar.

With regard to the regulation of SCD and PCE, numerous studies have been reported. The activities of SCD and PCE in the liver are considered to be coordinately controlled in 
response to hormonal, dietary and pharmacological changes [4-6, 15, 29, 30]. The present study showed the coordinated up-regulation of these enzymes in ZF rats that are spontaneously obese and non-diabetic. Similarly, SCD and PCE are both up-regulated in the liver of SHR/NDcp rats that is spontaneously type 2 diabetic and obese [18]. This coordinated regulation of SCD and PCE is considered to be mediated by transcription factors, sterol regulatory element binding protein-1c (SREBP-1c), carbohydrate responsive element binding protein, liver $\mathrm{X}$ receptor and peroxisome proliferator activated receptor $\alpha$, which regulate the expressions of SCD1 and Elovl6 [2]. Interestingly, Elovl6 deficiency is associated with the down-regulation of SCD1 gene expression [26]; conversely, liver-specific SCD1 knockout is associated with the reduced expression of Elovl6 [34]. These findings, taken together, may prompt one to conjecture close relationship between SCD1 and Elovl6. It is attractive to suspect that the similarity of SCD1 and Elovl6 in ER location, gene structures and coordinating functions of both proteins implicates that these genes could be derived from a common ancestral gene, a hypothesis that is presented by Matsuzaka and Shimano [35]. In this context, therefore, the case of GK rats must be very exceptional and surprising, the conclusion which could come from observation that the expressions of SCD1 and Elovl6 were not coordinately regulated in the liver of GK rats. It seems that a unique mechanism is involved in the regulation of SCD1 and/or Elovl6 in the liver of GK rats. The precise molecular mechanism for this, however, is currently unknown.

The present study clearly showed that ZF rats displayed a considerably low proportion of 20:4n-6 in the liver, whereas GK rats did not. The conversion of $18: 2 n-6$ to 6,9,12-octadecenoic acid (18:3n-6) is catalyzed by $\Delta 6$ desaturase, which is encoded by Fads2; $18: 3 n-6$ is then elongated to $20: 3 n-6$ by elongase that is encoded by Elovl5; $20: 3 n-6$ is desaturated to 20:4n-6 by $\Delta 5$ desaturase, which is encoded by Fads1 [36]. Therefore, changes in the activities of $\Delta 6$ and $\Delta 5$ desaturases are considered to be critical for the generation of the PUFAs of n-6 series [37]. The present results showed that hepatic contents of 18:2n-6 in the 
liver of ZL and ZF rats were almost equal, indicating no difference in the amounts of the substrate available for 20:4n-6 synthesis between ZL and ZF rats. On the other hand, the present study showed that the level of Fads1 mRNA in ZF rats was strikingly lower than that in ZL rats. This strong down-regulation of expression of Fads1 gene seems to result in the accumulation of 20:3n-6 and the decreases in the proportion and content of 20:4n-6 in hepatic lipids of ZF rats. These results are virtually consistent with the findings reported previously [31,38]. Moreover, it should be noted that the present study provided evidence that the levels of mRNAs for Fads1, Fads2 and Elovl5 in GK rats were significantly higher than those in ZF rats. These results, taken together, well elucidate the fact that the proportion of 20:4n-6 was lower and that of 20:3n-6 was higher in the liver of ZF rats and that these fatty acids were at normal proportions in the liver of GK rats (Fig. 6). Thus, the metabolism of PUFAs in the liver of GK rats is largely normal.

The present study revealed the higher contents of 18:1n-9 (530\%), 16:1n-7 (830\%), 18:1n-7 (270\%) and 16:0 (198\%) in the liver of ZF rats. The hepatic profile of MUFA and saturated fatty acids (SFAs) in ZF rats is very similar to that of SHR/NDcp rats [18], which display spontaneous obesity, hypertension, hypertriglyceridemia and type2 diabetes [22]. These findings strongly imply that hepatic MUFA play a pathophysiologic role in the process of obesity or metabolic syndrome. However, little is known about pathophysiologic significance of the changes in hepatic content of MUFA. It has been well studied that ZF rats display hepatic and peripheral insulin resistance [39], hepatic steatosis [40], resistance to the inhibitory effects of insulin on VLDL production (i.e. hypertriglyceridemia) [41], and TAG accumulation in adipose tissues (i.e. obesity) [21]. Nevertheless, to our knowledge, there is little evidence to link the findings of up-regulations of MUFA biosynthesis and the findings of pathophysiologic processes in ZF rats together. Recently, Buqué et al. has demonstrated that genes of fatty acid synthase, SCD1, malic enzyme and fatty acid translocase/CD36 are up-regulated in the liver of ZF rats and that the elevated expressions of these four genes 
significantly correlated with severity of hepatic steatosis, which is responsible for marked increase in hepatic content of TAG [42]. These findings strongly suggest increased formation of 16:0 and MUFA, although they did not present evidence with regard to the changes in fatty acid profile in the liver. An excess of SFAs such as 16:0 is known to cause ER stress [8-10], which in turn is causative of hepatic insulin resistance [43]. It is considered that hepatic ER stress may generally ensue when the hepatic capacity to degrade fatty acids, store fatty acids as TAG, and export TAG as VLDL is overwhelmed by hepatic de novo fatty acid synthesis. In insulin-resistant state, VLDL is overproduced as a safeguarding to protect against the further development of steatosis, leading to hypertriglyceridemia [44]. As a result, massive fatty acids are delivered to adipose tissues where the fatty acids are stored as TAG, which causes obesity. Once storage capacity of adipose tissues is exceeded, then net flux of fatty acids from visceral adipose tissues to the liver increases; this ectopic lipid accumulation in the liver worsens lipotoxic effects [45]. In the vicious cycle that leads to the progression of hepatic steatosis, hypertriglyceridemia, obesity and insulin resistance, fatty acid species plays a pivotal role. Notably, SFA are more toxic than MUFA in their capacity to induce ER stress [46, 47]. Namely, excess 16:0 alone is poorly incorporated into TAG, and co-treatment with 18:1n-9 or increased expression of SCD1 can divert 16:0 to TAG formation [48]. Thus, TAG containing 18:1n-9 may be stored as inert lipid stores with regard to lipotoxicity, so that SFA toxicity can be abrogated $[46,48]$. In this context, Stefan et al. have suggested that high hepatic SCD1 activity may regulate TAG accumulation in the liver and possibly protects from insulin resistance in obese humans [49]. Moreover, Li et al. showed that up-regulation of hepatic SCD1 may be a crucial adaptive mechanism in the prevention of liver damage and hepatitis in hepatic steatosis in mice [50]. Our present study showed striking increase in contents of both 16:0 and 18:1n-9, and up-regulations of both PCE (Elovl6) and SCD (SCD1) in the liver of ZF rats. Considering the pathophysiologic roles of 18:1n-9 as argued above, it seems likely that the elevated formation of 18:1n-9 from 16:0 by the coordinated action of Elovl6 and 
SCD1 in the liver of ZF rats is to maintain cellular 16:0 at low level enough to prevent ER stress and insulin resistance by sequestering fatty acids into inert TAG and by exporting fatty acids as VLDL-TAG. Additionally, PUFAs, in particular 20:4n-6, strongly suppress expression of SREBP-1c [51], and 18:1n-9 as well as PUFAs is shown to increase Insig-1, a protein that retains SREBP-1c in ER membrane, leading to prevention of maturation of SREBP-1c to its nuclear form [52]. The present study showed that hepatic content of 20:4n-6 is lower by $30 \%$ and that of 18:1n-9 is higher (530\%) than control rats. It seems likely, therefore, that the alteration occurred in fatty acid profile in the liver of ZF rats tends to improve inappropriately elevated lipogenesis. Nevertheless, insulin may continue to stimulate SREBP-1c activity and lipogenesis in livers of ZF rats that are otherwise insulin resistance. Thus, the combination of insulin resistance (inappropriate gluconeogenesis) and insulin sensitivity (elevated lipogenesis) may establish a vicious cycle that aggravates hyperinsulinemia and insulin resistance in ZF rats. On the other hand, GK rats display hepatic and peripheral insulin resistance (type 2 diabetes) [53] and a slight increase in VLDL-TAG [54], without obesity. Surprisingly, the present study has shown the up-regulation of SCD1, but not Elovl6, and little change in contents of MUFA in the liver of GK rats. The phenomenon that the expression of SCD1 is significantly elevated in the liver in GK rats is particularly interesting, but it is yet unclear how the up-regulation of SCD1 plays pathophysiologic role in the processes of type 2 diabetes in GK rats.

There is growing evidence that 16:1n-7 has notable physiologic benefits. Adipose-tissue derived 16:1n-7 was reported to act as a lipokine, improve insulin action and suppress hepatosteatosis through down-regulation of hepatic SCD1 and decreased TG synthesis [13]. A recent study has shown that $16: 1 \mathrm{n}-7$ supplemented with diet to mice improves insulin sensitivity, suppresses liver inflammatory response and paradoxically induces hepatic steatosis through up-regulation of fatty acid synthase in the liver [55]. Thus, physiologic significance of 16:1n-7 as a lipokine has not been fully elucidated. On the other hand, a 
number of studies indicate that $16: 1 \mathrm{n}-7$ is capable of reducing ER stress in many types of cells including hepatocytes [56, 57]. More recently, Tripathy and Jump has provided evidence strongly suggesting that 18:1n-7 produced from 16:1n-7 by Elovl5 down-regulates gluconeogenesis in the liver [58]. Our present study showed that 16:1n-7 content was markedly higher (830\%) in the liver of ZF rats and that hepatic content of 16:1n-7 in GK rats tended to be higher (172\%), the difference being not statistically significant. However, further studies are required to determine whether $16: 1 n-7$ produced in the liver per se and 18:1n-7 produced from 16:1n-7 act as a factor to prevent or aggravate metabolic disorder in these rats. Many attempts have been made to understand the physiological roles of SCD1, Elovl6 and Elovl5 by means of genetic engineering of animals or cells. In this regard, however, model animals that are spontaneously altered in the regulation of Elovl6 independently of SCD1 expression have not been found, so that little has been resolved about whether regulation of SCD1 in concert with Elovl6 is required for the formation of 18:1n-9 in vivo in the liver. The present study provided evidence that up-regulation of Elovl6 along with SCD1 is indispensable in the augmented formation of $18: 1 n-9$ in the liver. To our knowledge, this study is the first to constitute insight in the relationships between fatty acid desaturation and elongation and fatty acid profile in the liver of GK rats.

Acknowledgments This work was supported by a Grant-in-Aid for Scientific Research from the Ministry of Education, Culture, Sports, Science and Technology of Japan.

\section{REFERENCES}

1. Ntambi JM, Miyazaki M (2004) Regulation of stearoyl-CoA desaturases and role in metabolism. Prog Lipid Res 43:91-104

2. Jump DB (2011) Fatty acid regulation of hepatic lipid metabolism. Curr Opin Clin Nutr Metab Care 14:115-120 
3. Strable MS, Ntambi JM (2010) Genetic control of de novo lipogenesis: role in diet-induced obesity. Crit Rev Biochem Mol Biol 45:199-214

4. Wang Y, Botolin D, Christian B, Busik J, Xu J, Jump DB (2005) Tissue-specific, nutritional, and developmental regulation of rat fatty acid elongases. J Lipid Res 46:706-715

5. Wang Y, Botolin D, Xu J, Christian B, Mitchell E, Jayaprakasam B, Nair M, Peters JM, Busik J, Olson LK, Jump DB (2006) Regulation of hepatic fatty acid elongase and desaturase expression in diabetes and obesity. J Lipid Res 47:2028-2041

6. Kudo N, Toyama T, Mitsumoto A, Kawashima Y (2003) Regulation by carbohydrate and clofibric acid of palmitoyl-CoA chain elongation in the liver of rats. Lipids 38:531-537

7. Miyazaki M, Kim Y-C, Gray-Keller MP, Attie AD, Ntambi JM (2000) The Biosynthesis of hepatic cholesterol esters and triglycerides is impaired in mice with a disruption of the gene for stearoyl-CoA desaturase 1. J Biol Chem 275:30132-30138

8. Wei Y, Wang D, Topczewski F, Pagliassotti MJ (2006) Saturated fatty acids induce endoplasmic reticulum stress and apoptosis independently of ceramide in liver cells. Am J Physiol Endocrinol Metab 291:E275-E281

9. Wei Y, Wang D, Gentile CL, Pagliassotti MJ (2009) Reduced endoplasmic reticulum luminal calcium links saturated fatty acid-mediated endoplasmic reticulum stress and cell death in liver cells. Mol Cell Biochem 331:31-40

10. Ariyama H, Kono N, Matsuda S, Inoue T, Arai H (2010) Decrease in membrane phospholipid unsaturation induces unfolded protein response. J Biol Chem 285:22027-22035 11. Dixon JL, Furukawa S, Ginsberg HN (1991) Oleate stimulates secretion of apolipoprotein B-containing lipoproteins from Hep G2 cells by inhibiting early intracellular degradation of apolipoprotein B. J Biol Chem 266:5080-5086

12. Legrand P, Catheline D, Fichot M-C, Lemarchal P (1997) Inhibiting $\Delta$ 9-desaturase activity impairs triacylglycerol secretion in cultured chicken hepatocytes. J Nutr 127:249-256

13. Cao H, Gerhold K, Mayers JR, Wiest MM, Watkins SM, Hotamisligil GS (2008) 
Identification of a lipokine, a lipid hormone linking adipose tissue to systemic metabolism. Cell 134:933-944

14. Gutiérrez-Juárez R, Pocai A, Mulas C, Ono H, Bhanot S, Monia BP, Rossetti L (2006) Critical role of stearoyl-CoA desaturase-1 (SCD1) in the onset of diet-induced hepatic insulin resistance. J Clin Invest 116:1686-1695

15. Kawashima Y, Kozuka H (1982) Increased activity of stearoyl-CoA desaturation in liver from rat fed clofibric acid. Biochim Biophys Acta 713:622-628

16. Ge F, Zhou S, Hu C, Lobdell 4th H, Berk PD (2010) Insulin- and leptin-regulated fatty acid uptake plays a key causal role in hepatic steatosis in mice with intact leptin signaling but not in $o b / o b$ or $d b / d b$ mice. Am J Physiol Gastrointest Liver Physiol 299:G855-G866 17. Toyama T, Kudo N, Hibino Y, Mitsumoto A, Nishikawa M, Kawashima Y (2007) Effects of pioglitazone on stearoyl-CoA desaturase in obese Zucker fa/fa rats. J Pharmacol Sci 104:137-145

18. Tanaka S, Yagi Y, Yamazaki T, Mitsumoto A, Kobayashi D, Kudo N, Kawashima Y (2012) Characterization of fatty acid profile in the liver of SHR/NDmcr-cp $(c p / c p)$ rats, a model of the metabolic syndrome. Biol Pharm Bull 35:184-191 19. Li M, Fu W, Li X-A (2010) Differential fatty acid profile in adipose and non-adipose tissues in obese mice. Int J Clin Exp Med 3:303-307

20. Chen H, Charlat O, Tartaglia LA, Woolf EA, Weng X, Ellis SJ, Lakey ND, Culpepper J, More KJ, Breitbart RE, Duyk GM, Tepper RI, Morgenstern JP (1996) Evidence that the diabetes gene encodes the leptin receptor: Identification of a mutation in the leptin receptor gene in $d b / d b$ mice. Cell 84:491-495

21. Phillips MS, Liu Q, Hammond HA, Dugan V, Hey PJ, Caskey CT, Hess JF (1996) Leptin receptor missense mutation in the fatty Zucker rat. Nat Genet 13:18-19

22. Kawai K, Sakairi T, Harada S, Shinozuka J, Ide M, Sato H, Tanaka M, Toriumi W, Kume E (2012) Diet modification and its influence on metabolic and related pathological alterations 
in the SHR/NDmcr-cp rat, an animal model of the metabolic syndrome. Exp Toxicol Pathol 64:333-338

23. Goto Y, Kakizaki M, Masaki N (1975) Spontaneous diabetes produced by selective breeding of normal Wistar rats. Proc Jpn Acad 51:80-85

24. Portha B, Serradas P, Bailbé D, Suzuki K, Goto Y, Giroix M-H (1991) $\beta$-cell insensitivity to glucose in the GK rat, a spontaneous nonobese model for type II diabetes. Diabetes $40: 486-491$

25. Portha B (2005) Programmed disorders of $\beta$-cell development and function as one cause for type 2 diabetes ? The GK rat paradigm. Diabetes Metab Res Rev 21:495-504

26. Matsuzaka T, Shimano H, Yahagi N, Kato T, Atsumi A, Yamamoto T, Inoue N, Ishikawa M, Okada S, Ishigaki N, Iwasaki H, Iwasaki Y, Karasawa T, Kumadaki S, Matsui T, Sekiya M, Ohashi K, Hasty AH, Nakagawa Y, Takahashi A, Suzuki H, Yatoh S, Sone H, Toyoshima H, Osuga J, Yamada N (2007) Crucial role of a long-chain fatty acid elongase, Elovl6, in obesity-induced insulin resistance. Nat Med 13:1193-1202

27. Lowry OH, Rosebrough NJ, Farr AL, Randall RJ (1951) Protein measurement with the folin phenol reagent. J Biol Chem 193:265-275

28. Bligh EG, Dyer WJ (1959) A rapid method of total lipid extraction and purification. Can J Biochem Physiol 37:911-917

29. Yamazaki T, Wakabayashi M, Ikeda E, Tanaka S, Sakamoto T, Mitsumoto A, Kudo N, Kawashima Y (2012) Induction of 1-acylglycerophosphocholine acyltransferase genes by fibrates in the liver of rats. Biol Pharm Bull 35:1509-1515

30. Kawashima Y, Kozuka H (1985) Regulation of palmitoyl-CoA chain elongation and linoleoyl-CoA chain elongation in rat liver microsomes and the differential effects of peroxisome proliferators, insulin and thyroid hormone. Biochim Biophys Acta 834:118-123 31. Fèvre C, Bellenger S, Pierre A-M, Minville M, Bellenger J, Gresti J, Rialland M, Narce M, Tessier C (2011) The metabolic cascade leading to eicosanoid precursors - desaturases, 
elongases, and phospholipases $\mathrm{A}_{2}$ - is altered in Zucker fatty rats. Biochim Biophys Acta 1811:409-417

32. Yamazaki T, Okada H, Sakamoto T, Sunaga K, Tsuda T, Mitsumoto A, Kudo N, Kawashima Y (2012) Differential induction of stearoyl-CoA desaturase 1 and 2 genes by fibrates in the liver of rats. Biol Pharm Bull 35:116-120

33. Green CD, Ozguden-Akkoc CG, Wang Y, Jump DB, Olson LK (2010) Role of fatty acid elongases in determination of de novo synthesized monounsaturated fatty acid species. J Lipid Res 51:1871-1877

34. Miyazaki M, Flowers MT, Sampath H, Chu K, Otzelberger C, Liu X, Ntambi JM (2007) Hepatic stearoyl-CoA desaturase-1 deficiency protects mice from carbohydrate-induced adiposity and hepatic steatosis. Cell Metab 6:484-496

35. Matsuzaka T, Shimano H (2009) Elovl6: a new player in fatty acid metabolism and insulin sensitivity. J Mol Med 87:379-384

36. Guillou H, Zadravec D, Martin PGP, Jacobsson A (2010) The key roles of elongases and desaturases in mammalian fatty acid metabolism: Insights from transgenic mice. Prog Lipid Res 49:186-199

37. Marcel YL, Christiansen K, Holman RT (1968) The preferred metabolic pathway from linoleic acid to arachidonic acid in vitro. Biochim Biophys Acta 164:25-34

38. Blond J-P, Henchiri C, Bézard J (1989) $\Delta 6$ and $\Delta 5$ desaturase activities in liver from obese Zucker rats at different ages. Lipids 24:389-395

39. Terrettaz J, Jeanrenaud B (1983) In vivo hepatic and peripheral insulin resistance in genetically obese (fa/fa) rats. Endocrinology 112:1346-1351

40. Gary-Bobo M, Elachouri G, Gallas JF, Janiak P, Marini P, Ravinet-Trillou C, Chabbert M, Cruccioli N, Pfersdorff C, Roque C, Arnone M, Croci T, Soubrié P, Oury-Donat F, Maffrand JP, Scatton B, Lacheretz F, Le Fur G, Herbert JM, Bensaid M (2007) Rimonabant reduces obesity-associated hepatic steatosis and features of metabolic syndrome in obese Zucker fa/fa 
rats. Hepatology 46:122-129

41. Sparks JD, Sparks CE (1994) Obese Zucker ( $f a / f a)$ rats are resistant to insulin’s inhibitory effect on hepatic apo B secretion. Biochem Biophys Res Commun 205:417-422

42. Buqué X, Martínez MJ, Cano A, Miquilena-Colina ME, García-Monzón C, Aspichueta P, Ochoa B (2010) A subset of dysregulated metabolic and survival genes is associated with severity of hepatic steatosis in obese Zucker rats. J Lipid Res 51:500-513

43. Özcan U, Cao Q, Yilmaz E, Lee A-H, Iwakoshi NN, Özdelen E, Tuncman G, Görgün C, Glimcher LH, Hotamisligil GS (2004) Endoplasmic reticulum stress links obesity, insulin action, and type 2 diabetes. Science 306:457-461

44. Ota T, Gayet C, Ginsberg HN (2008) Inhibition of apolipoprotein B100 secretion by lipid-induced hepatic endoplasmic reticulum stress in rodents. J Clin Invest 118:316-332 45. Virtue S, Vidal-Puig A (2010) Adipose tissue expandability, lipotoxicity and the metabolic syndrome - an allostatic perspective. Biochim Biophys Acta 1801:338-349

46. Alkhouri N, Dixon LJ, Feldstein AE (2009) Lipotoxicity in nonalcoholic fatty liver disease: Not all lipids are created equal. Expert Rev Gastroenterol hepatol 3:445-451 47. Malhi H, Bronk SF, Werneburg NW, Gores GJ (2006) Free fatty acids induce JNK-dependent hepatocyte lipoapoptosis. J Biol Chem 281:12093-12101 48. Listenberger LL, Han X, Lewis SE, Cases S, Farese RV Jr, Ory DS, Schaffer JE (2003) Triglyceride accumulation protects against fatty acid-induced lipotoxicity. Proc Natl Acad Sci USA 100:3077-3082

49. Stefan N, Peter A, Cegan A, Staiger H, Machann J, Schick F, Claussen CD, Fritsche A, Häring H-U, Schleicher E (2008) Low hepatic stearoyl-CoA desaturase 1 activity is associated with fatty liver and insulin resistance in obese humans. Diabetologia 51:648-656 50. Li ZZ, Berk M, McIntyre TM, Feldstein AE (2009) Hepatic lipid partitioning and liver damage in nonalcoholic fatty liver disease. Role of stearoyl-Co desaturase. J Biol Chem 284:5637-5644 
51. Yoshikawa T, Shimano H, Yahagi N, Ide T, Amemiya-Kudo M, Matsuzaka T, Nakakuki M, Tomita S, Okazaki H, Tamura Y, lizuka Y, Ohashi K, Takahashi A, Sone H, Osuga J, Gotoda T, Ishibashi S, Yamada N (2002) Polyunsaturated fatty acids suppress sterol regulatory element-binding protein 1c promoter activity by inhibition of Liver X receptor (LXR) binding to LXR response elements. J Biol Chem 277:1705-1711

52. Lee JN, Zhang X, Feramisco JD, Gong Y, Ye J (2008) Unsaturated fatty acids inhibit proteasomal degradation of Insig-1 at a postubiquitination step. J Biol Chem 283:33772-33783

53. Bisbis S, Bailbe D, Tormo M-A, Picarel-Blanchot F, Derouet M, Simon J, Portha B (1993) Insulin resistance in the GK rat: decreased receptor number but normal kinase activity in liver. Am J Physiol Endocrinol Metab 265:E807-E813

54. Yamane M, Jiao S (Sho N), Kihara S, Shimomura I, Yanagi K, Tokunaga K, Kawata S, Odaka H, Ikeda H, Yamashita S, Kameda-Takemura K, Matsuzawa Y (1995) Increased proportion of plasma apoB-48 to apoB-100 in non-insulin-dependent diabetic rats: contribution of enhanced apoB mRNA editing in the liver. J Lipid Res 36:1676-1685

55. Guo X, Li H, Xu H, Halim V, Zhang W, Wang H, Ong KT, Woo s-H, Walzem RL, Mashek DG, Dong H, Lu F, Wei L, Huo Y, Wu C (2012) Palmitoleate induces hepatic steatosis but suppresses liver inflammatory response in mice. PLoS ONE 7:e39286

56. Akazawa Y, Cazanave S, Mott JL, Elmi N, Bronk SF, Kohno S, Charlton MR, Gores GJ (2010) Palmitoleate attenuates palmitate-induced Bim and PUMA up-regulation and hepatocyte lipoapoptosis. J Hepatol 52:586-593

57. Kadotani A, Tsuchiya Y, Hatakeyama H, Katagiri H, Kanzaki M (2009) Different impacts of saturated and unsaturated free fatty acids on COX-2 expression in $\mathrm{C}_{2} \mathrm{C}_{12}$ myotubes. Am $\mathrm{J}$ Physiol Endocrinol Metab 297:E1291-E1303

58. Tripathy S, Jump DB (2013) Elovl5 regulates the mTORC2-Akt-FOXO1 pathway by controlling hepatic cis-vaccenic acid synthesis in diet-induced obese mice. J Lipid Res 
54:71-84 
Figure legends

Fig. 1 Activities of SCD in hepatic microsomes of STZ, GK and ZF rats. Values represent mean \pm SD $(n=4)$, ${ }^{a}$ b Differences without a common superscript are statistically significant $(P<0.05)$

Fig. 2 Differences in content ( $\mu$ mole/g liver) of fatty acids in hepatic lipids between GK and WI rats and between ZF and ZL rats. With regard to each fatty acid, differences in content between the means of WI and GK rats and between ZL and ZF rats were calculated from the data in Table 2.

Fig. 3 Activities of PCE (A) and POCE (B) in hepatic microsomes of GK and ZF rats. Values represent mean \pm SD $(n=4) .{ }^{\text {a, b }}$ Differences without a common superscript are statistically significant $(P<0.05)$.

Fig. 4 Levels of mRNA encoding SCD1, SCD2, Elovl5, Elovl6, Fads1 and Fads2 in the liver of GK and ZF rats. Values represent mean \pm SD $(n=4)$. ${ }^{a, b, c}$ Differences without a common superscript are statistically significant $(P<0.05)$. If no superscript appears, the differences in the means are not significant $(P>0.05)$.

Fig. 5 Diagram of enzymes regulating synthesis of 16:1n-7, 18:1n-7 and 18:1n-9.

Fig. 6 Diagram of enzymes regulating synthesis of 20:3n-6 and 20:4n-6 
Table 1 Sequences of primers used for real-time PCR

\begin{tabular}{lll}
\hline & Primer sequence (5' -3') & Accession No. \\
\hline Elovl5 & F : ACCACCATGCCACTATGCTCA & AB071985 \\
& $\mathrm{R}:$ GGACGTGGATGAAGCTGTTG & \\
Elovl6 & $\mathrm{F}:$ AGAACACGTAGCGACTCCGAA & AB071986 \\
& $\mathrm{R}:$ CAAACGCGTAAGCCCAGAAT & \\
Fads1 & $\mathrm{F}:$ TACAGGCAACCTGCAACGTTC & NM_053445 \\
& $\mathrm{R}:$ GGTGCCACCTTGTGGTAGTTGT & \\
Fads2 & $\mathrm{F}:$ GCCACTTAAAGGGTGCCTCC & BC081776 \\
& $\mathrm{R}:$ TGCAGGCTCTTTATGTCGGG & \\
SCD1 & $\mathrm{F}:$ TCACCTTGAGAGAAGAATTAGCA & \multirow{2}{*}{ J02585 } \\
& $\mathrm{R}:$ TTCCCATTCCCTTCACTCTGA & \\
SCD2 & $\mathrm{F}:$ TGCACCCCCAGACACTTGTAA & AB032243 \\
& $\mathrm{R}:$ GGATGCATGGAAACGCCATA & \\
$\beta$-Actin & $\mathrm{F}:$ TGCAGAAGGAGATTACTGCC & V01217 \\
& $\mathrm{R}:$ CGCAGCTCAGTAACAGTCC & \\
\hline
\end{tabular}


Table 2 Fatty acid profile (mole \%) of hepatic lipid of GK and ZF rats

\begin{tabular}{|c|c|c|c|c|c|c|c|c|c|c|c|c|}
\hline \multirow{2}{*}{$\begin{array}{l}\text { Fatty acids } \\
16: 0\end{array}$} & \multicolumn{3}{|c|}{ WI } & \multicolumn{3}{|c|}{ GK } & \multicolumn{3}{|c|}{ ZL } & \multicolumn{3}{|c|}{$\mathrm{ZF}$} \\
\hline & 25.47 & \pm & 1.26 & 26.30 & \pm & 2.09 & 28.87 & \pm & 5.92 & 32.07 & \pm & 2.67 \\
\hline $16: 1 n-7$ & 1.63 & \pm & $0.23^{\mathrm{a}}$ & 2.70 & \pm & $0.13^{\mathrm{a}}$ & 1.43 & \pm & $0.61^{\mathrm{a}}$ & 6.70 & \pm & $1.12^{\mathrm{b}}$ \\
\hline 18:0 & 16.70 & \pm & $0.59^{\mathrm{a}}$ & 16.25 & \pm & $1.57^{\mathrm{a}}$ & 17.52 & \pm & $1.93^{\mathrm{a}}$ & 10.96 & \pm & $2.56^{\mathrm{b}}$ \\
\hline $18: 1 n-9$ & 7.47 & \pm & $0.52^{\mathrm{a}}$ & 8.97 & \pm & $0.68^{\mathrm{a}}$ & 7.05 & \pm & $0.87^{\mathrm{a}}$ & 20.71 & \pm & $2.19^{\mathrm{b}}$ \\
\hline $18: 1 n-7$ & 4.01 & \pm & $0.30^{\mathrm{ac}}$ & 5.28 & \pm & $0.20^{\mathrm{b}}$ & 3.09 & \pm & $0.34^{\mathrm{a}}$ & 4.66 & \pm & $0.92^{\mathrm{bc}}$ \\
\hline $18: 2 n-6$ & 21.62 & \pm & $0.74^{\mathrm{a}}$ & 17.29 & \pm & $1.67^{\mathrm{b}}$ & 23.22 & \pm & $0.68^{\mathrm{a}}$ & 14.05 & \pm & $1.68^{\mathrm{C}}$ \\
\hline $18: 3 n-3$ & 0.46 & \pm & 0.03 & 0.42 & \pm & 0.08 & 0.36 & \pm & 0.05 & 0.35 & \pm & 0.07 \\
\hline $20: 3 n-9$ & 0.06 & \pm & 0.03 & 0.06 & \pm & 0.01 & 0.11 & \pm & 0.05 & 0.12 & \pm & 0.11 \\
\hline $20: 3 n-6$ & 1.24 & \pm & $0.15^{\mathrm{a}}$ & 0.97 & \pm & $0.11^{\mathrm{ac}}$ & 0.75 & \pm & $0.17^{\mathrm{bc}}$ & 1.34 & \pm & $0.30^{\mathrm{a}}$ \\
\hline $20: 4 n-6$ & 14.47 & \pm & $0.72^{\mathrm{a}}$ & 15.61 & \pm & $1.02^{\mathrm{a}}$ & 12.87 & \pm & $2.84^{\mathrm{a}}$ & 5.11 & \pm & $1.24^{\mathrm{b}}$ \\
\hline $20: 5 n-3$ & 1.13 & \pm & 0.10 & 0.97 & \pm & 0.12 & 0.96 & \pm & 0.33 & 0.81 & \pm & 0.18 \\
\hline $22: 5 n-3$ & 1.62 & \pm & $0.15^{\mathrm{a}}$ & 1.46 & \pm & $0.27^{\mathrm{ac}}$ & 1.13 & \pm & $0.53^{\mathrm{ac}}$ & 0.83 & \pm & $0.18^{\mathrm{bc}}$ \\
\hline $22: 6 n-3$ & 4.14 & \pm & $0.15^{\mathrm{a}}$ & 3.75 & \pm & $0.32^{\mathrm{ac}}$ & 2.68 & \pm & $1.25^{\mathrm{ac}}$ & 2.30 & \pm & $0.77^{\mathrm{bc}}$ \\
\hline Total $(\mu \mathrm{mol} / \mathrm{g}$ liver $)$ & 87.58 & \pm & $4.58^{\mathrm{a}}$ & 91.27 & \pm & $10.84^{\mathrm{a}}$ & 99.82 & \pm & $18.07^{\mathrm{a}}$ & 179.78 & \pm & $44.97^{\mathrm{b}}$ \\
\hline
\end{tabular}

Values represent mean \pm SD $(n=4)$. Differences in horizontal means without a common superscript (a, b, c) are significant ( $p<0.05$ ). If no superscript appears, the differences in the means are not significant ( $P>0.05$ ). 
Fig. 1

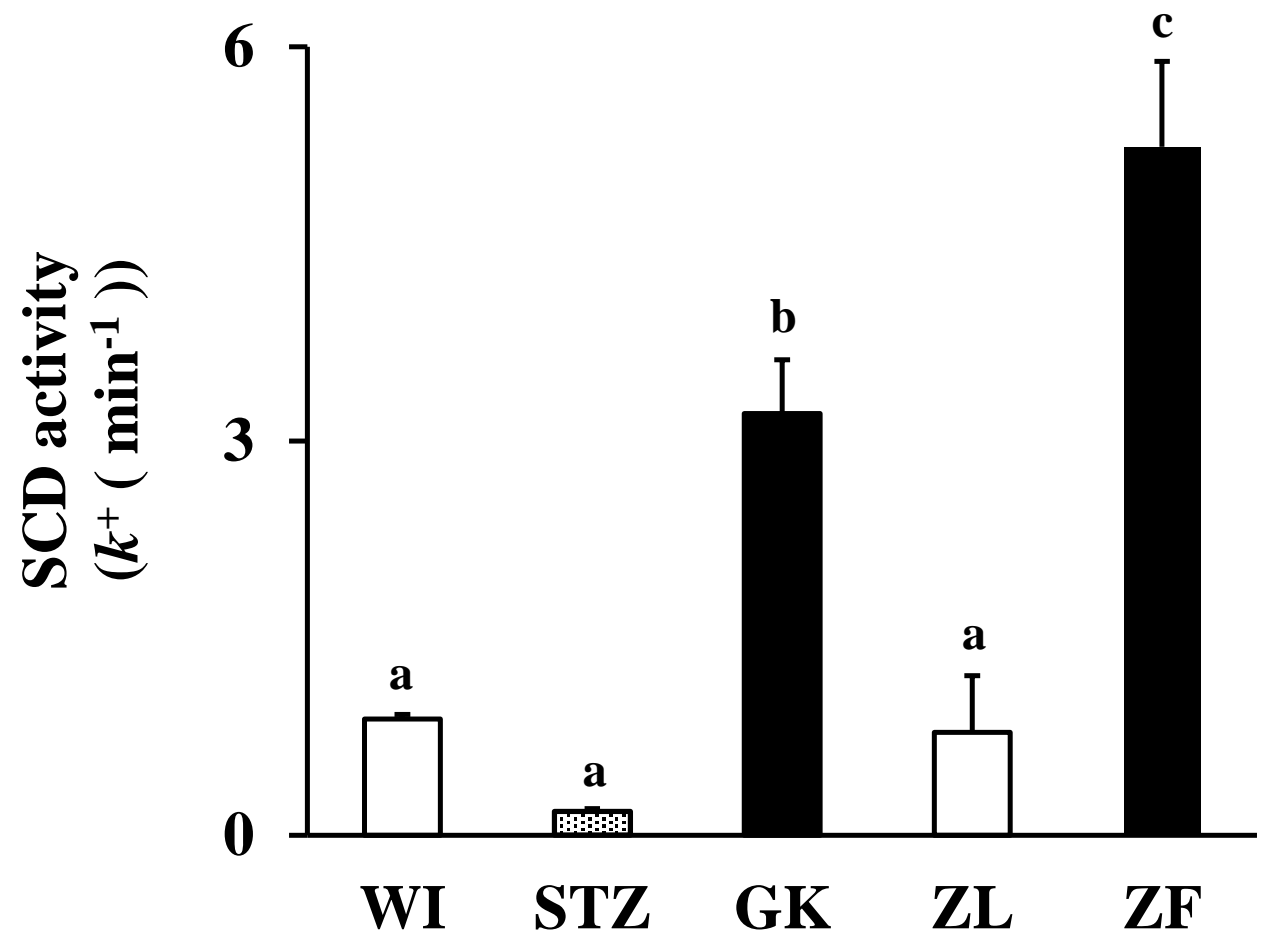


Fig. 2

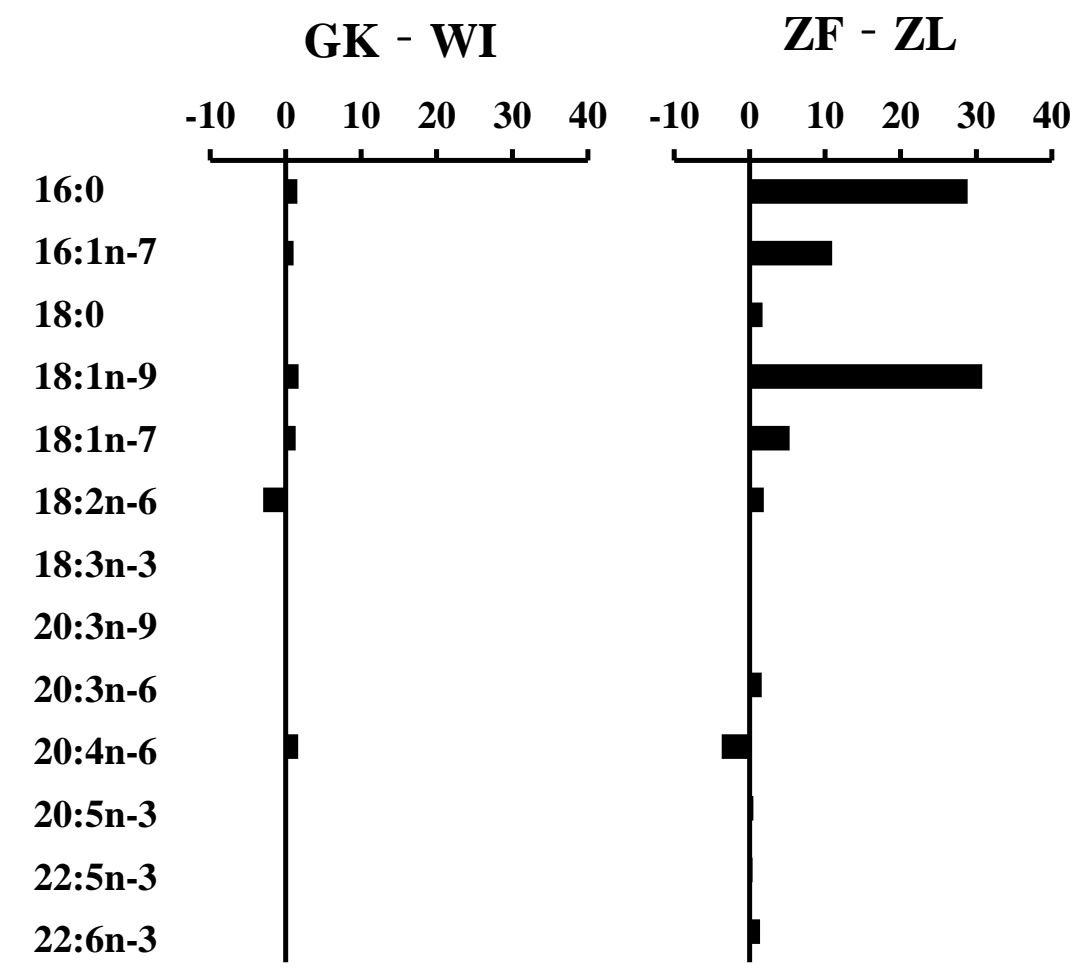


Fig. 3
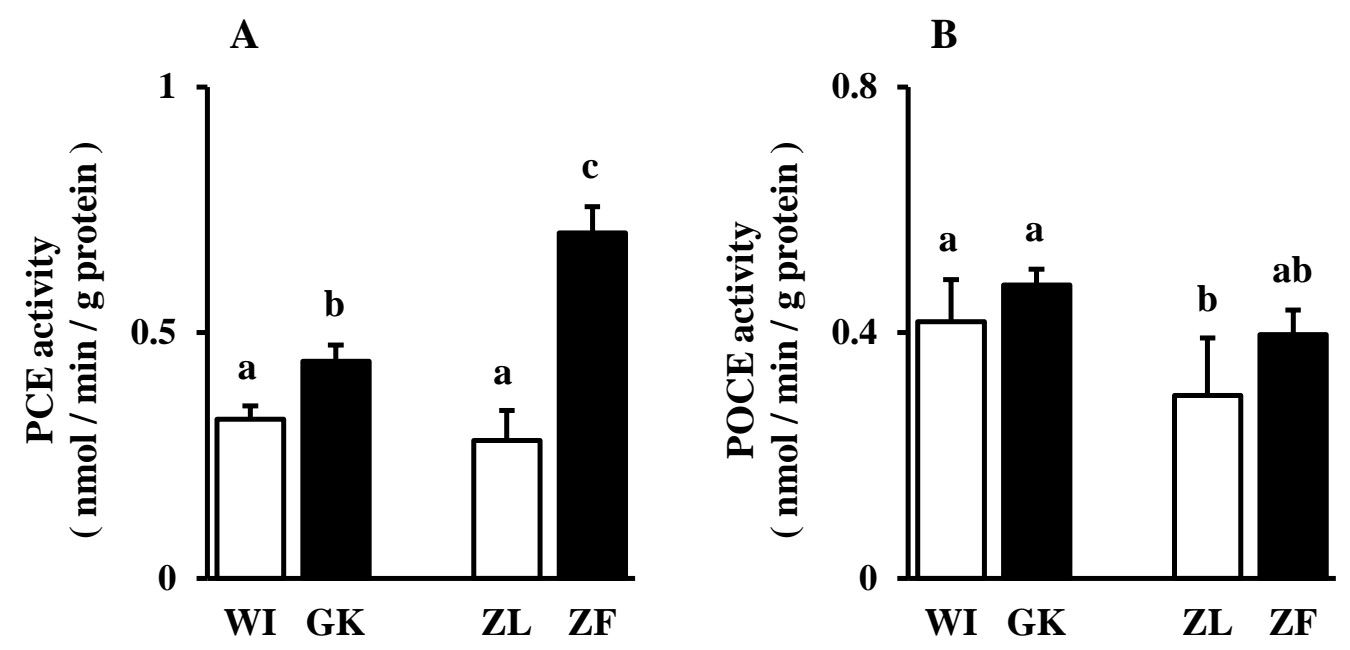
Fig. 4
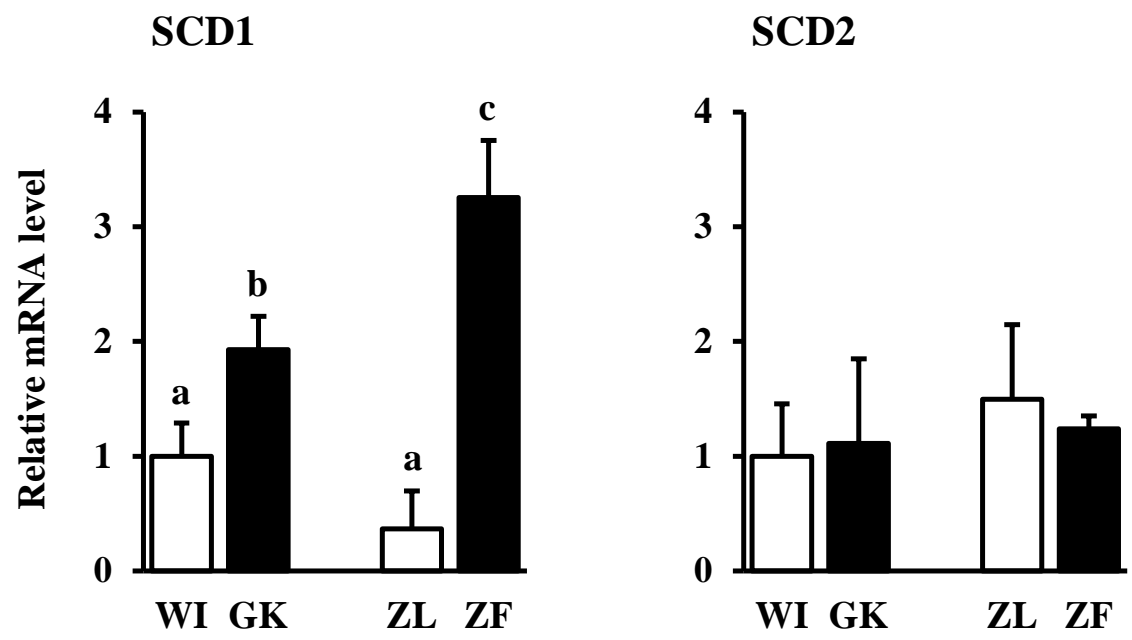

Elovl5

Elovl6
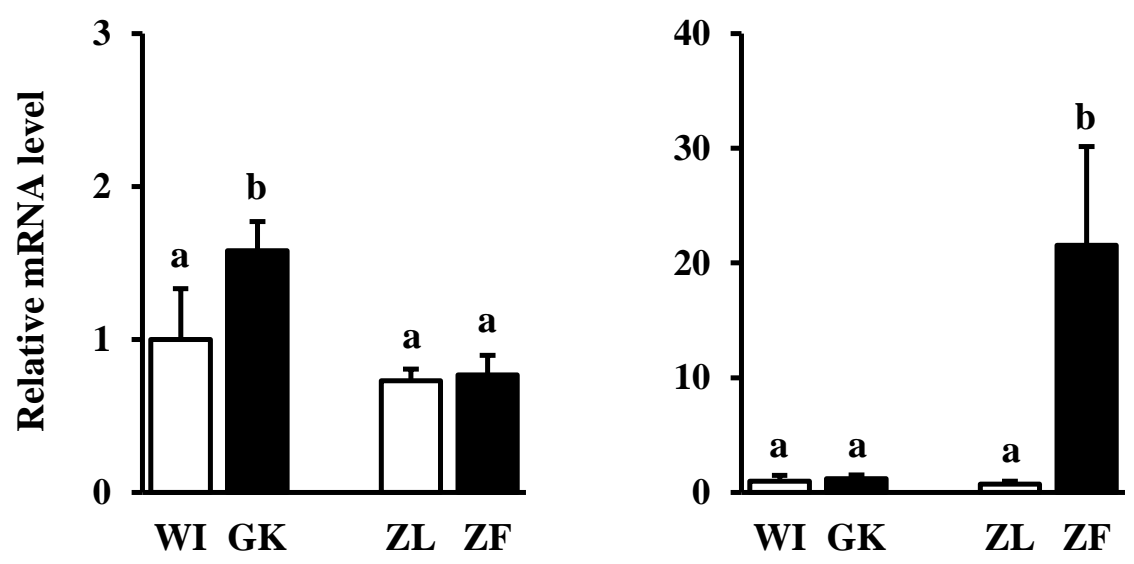

Fads1

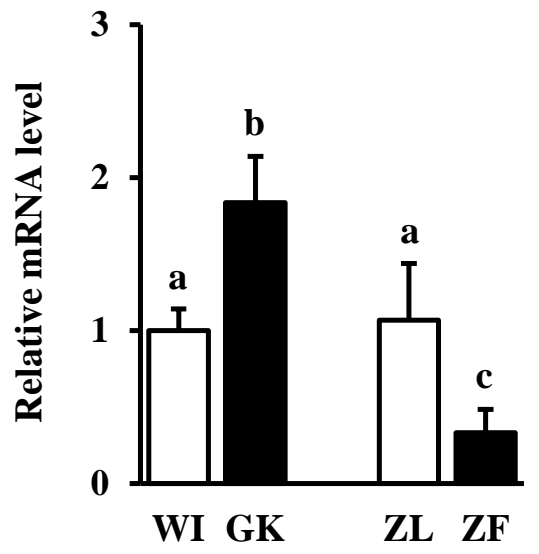

Fads2

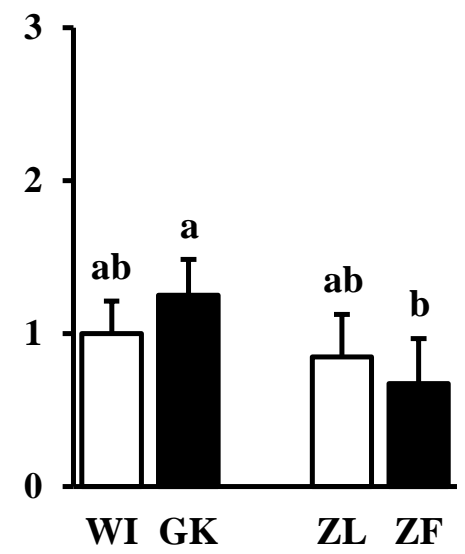


Fig. 5

GK rat

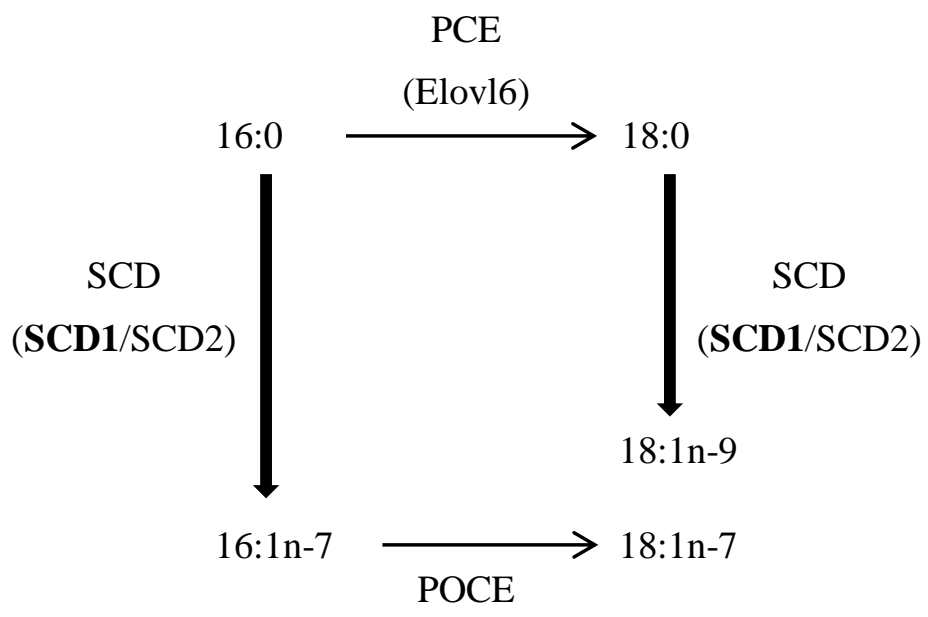

(Elovl5/Elov16)

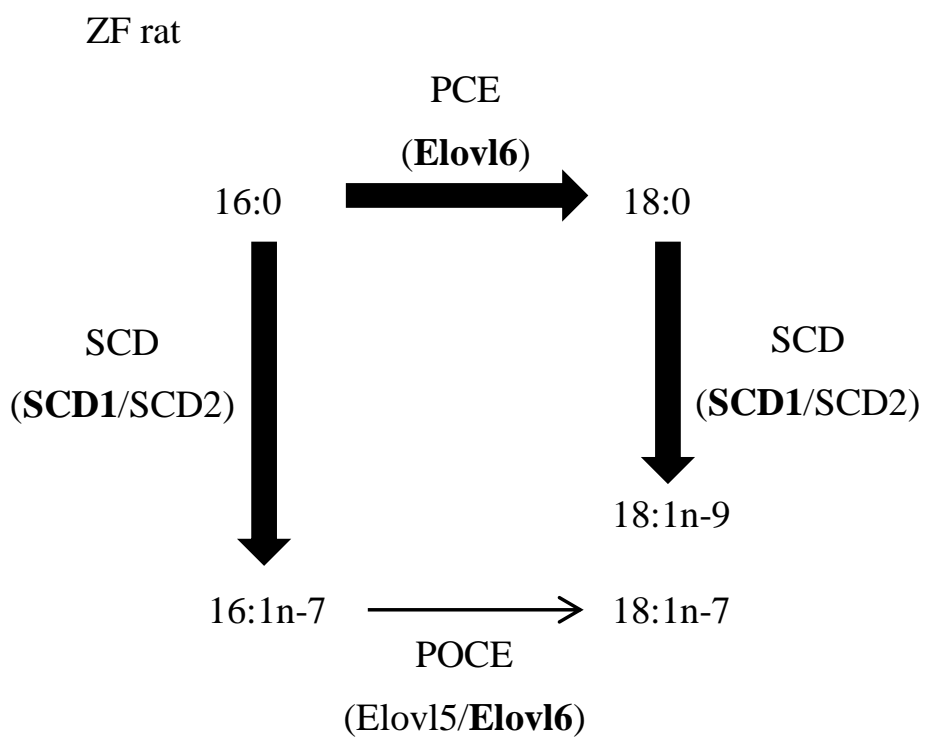


Fig. 6

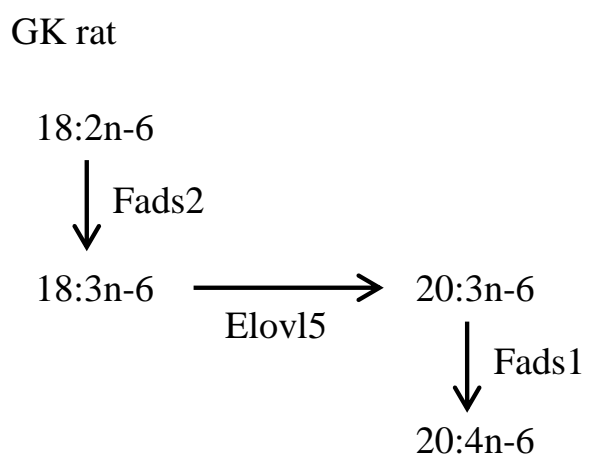

ZF rat

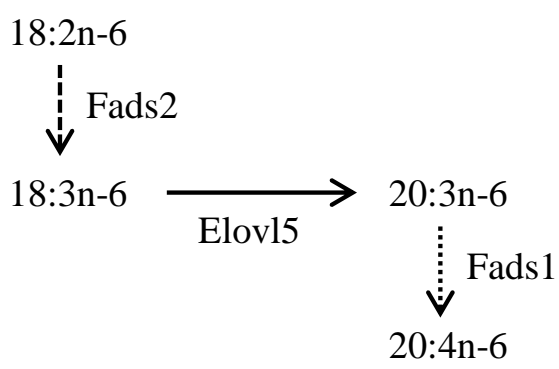

